\title{
Embracing customer-centric changes in publishing
}

\author{
Judy Verses* \\ Executive Vice-President, Research, Wiley, Inc., New York, NY, USA
}

There's no doubt that the STM publishing industry is rapidly changing. To lead, we will need to take hold of this change and drive it forward. I was eager to speak at the Academic Publishing in Europe conference at the beginning of this year about our strategies at Wiley and how we're not just bracing for change, we're leaning into it.

None of us in this industry will be able to drive change alone: we will need to work together and collaborate on solutions where it makes sense on behalf of the customers we serve. We can never lose sight that the researcher is our North Star, guiding us toward business strategies that will help them achieve their critical goals.

To lead change, any organization first needs a well thought out and long-term strategy. By looking at case studies of infamous company failures such as Kodak, Nokia and Yahoo, we see the importance of taking risks in our marketplace when it comes to disruptive change, and the potential for collapse when the fear to adapt and hold on to the old ways becomes too great. Organizations need to be constantly thinking about disruption, and often times must be ready to disrupt themselves.

In scholarly publishing, with the shift in business models and the funding landscape, publishers need to own that we're no longer meeting the needs of researchers. When we look at what's going on right now and how researchers are conducting their professional lives, we as publishers have not been keeping pace with the changes in researchers' behavior. Advances in technology over the past decade have made the consumer experience in other industries extremely efficient, and as they should, researchers have higher expectations for publishers. Because we weren't meeting the needs of our researchers, ResearchGate and Sci-Hub have emerged as disruptors. While it's important that there is competition in the marketplace to drive innovation, it is equally important to collaborate and work together when we recognize that we can't serve the needs of our customers alone.

From a Wiley perspective, our long-term goal is to continue to be a thought-leader in the publishing world: embracing Open Research and making the researcher's job easier and more efficient. To commit to the future, we need agile strategies that will enable open access, evolve business models, support a wider range of content formats and respond to newer approaches to accessing research content. We need to delight our customers, so they trust us to always put them first.

Putting our strategy of collaboration into action, Wiley's partnership with Projekt DEAL will help address the changing research environment. We have worked tirelessly and very closely with Projekt

\footnotetext{
*E-mail: jverses@wiley.com.
} 
DEAL for over two years to build a partnership arrangement that acknowledges the importance of both reading and publishing, and has the overarching goal of advancing Open Research, driving discovery, and developing and disseminating knowledge.

The most important part of what Wiley does is help researchers communicate and share their discoveries to advance knowledge. It is time for us to be bold and to take action to advance science. There will undoubtedly be bumps along the way, but we are extremely committed to working together to produce a more sustainable future in academic publishing. 